\title{
Baclofen withdrawal in a neonate
}

\author{
Senthuran Vijayarajah ${ }^{1}$, Mary Temple-Cooper ${ }^{2 *}$ and Firas Saker ${ }^{3}$ \\ ${ }^{1}$ Cleveland Clinic Children's Hospital, USA \\ ${ }^{2}$ Hillcrest Hospital - Cleveland Clinic, Department of Pharmacy, USA \\ ${ }^{3}$ Cleveland Clinic Children's Hospital, Department of Neonatology, USA
}

\section{Introduction}

Baclofen withdrawal in neonates is sparsely described in the literature [1,2]. Baclofen is a gamma-aminobutyric acid (GABA) agonist that is administered orally or intrathecally to decrease spasticity due to spinal cord injury. It is a safe medication in adults with known withdrawal effects. However, withdrawal from baclofen and treatment with baclofen in a neonate is sparsely reported in the literature with only 7 cases identified [1,3-5]. Our case highlights the use of baclofen to treat withdrawal of in-utero exposure in a neonate of a multi-drug GABA-nergic mother.

\section{Patient presentation}

The mother of our patient had good prenatal care except for GBS positivity prior to delivery. Maternal spastic paraplegia secondary to a resected spinal neuroblastoma at 4 months of age, gestational diabetes and pre-eclampsia complicated the pregnancy. The mother had ongoing chronic pain secondary to spasticity which was treated with baclofen (10 -20 mg every 4 hours with an average of 40-60 mg a day), lorazepam (4 mg at onset of pregnancy tapered to $3 \mathrm{mg}$ three times a day as needed) and pregabalin. The mother had good control of her symptoms during the pregnancy without any side effects; her postpartum course was complicated with eclampsia (first time seizure).

Our patient was a $2.24 \mathrm{~kg}$ male born at $361 / 7$ weeks gestation to a 26-year-old G1P0 mother. The patient's prenatal ultrasounds were normal. The neonate was delivered by elective cesarean section due to preeclampsia and maternal spastic hemiplegia. The neonate was small for gestational age (SGA) with initial hypotonia which was attributed to prematurity. The newborn exam was otherwise normal. The patient required free flow oxygen at delivery and had a short transition period in the neonatal intensive care unit prior to being transferred to the regular newborn nursery.

The patient showed signs of intermittent episodes of limb and head jitteriness at 24 hours of life in the newborn nursery; vital signs were normal. He was re-admitted to the NICU on day of life 4 for signs of neonatal withdrawal symptoms. The patient had high pitched crying, restlessness, increased work of breathing with nasal flaring and hypertonicity. The neonatal abstinence score (NAS) was 14 at that time and he was started on phenobarbital $(10 \mathrm{mg} / \mathrm{kg}$ loading dose followed by a $3 \mathrm{mg} / \mathrm{kg} /$ day maintenance dose). NAS remained between $6-10$ and clonidine ( $4 \mathrm{mcg} / \mathrm{kg}$ every 4 hours) was started on day 5 of life. The patient experienced minimal improvement; thus, baclofen was started on day 6 of life at $1 \mathrm{mg} / \mathrm{kg} /$ day divided every 6 hours with continuation of phenobarbital and weaning of clonidine. NAS scores improved significantly (scores of 3-6) within four hours of initiating baclofen. NAS scores remained less than or equal to 3 after twelve hours of

therapy. A baclofen wean was initiated after three days of stabilization. The baclofen was weaned by $25 \%$ of the initial dose every other day and was discontinued after a week of therapy. Total treatment time with baclofen was 10 days. The patient's heart rate, blood pressure and temperature were within normal limits and comparable before and after treatment. However, respiratory rate improved significantly after starting treatment with baclofen (went from 40-80 to 26-61 breaths per minute). His mother opted to formula feed him and his weight increased appropriately throughout the stay. The patient was observed for 2 days after discontinuation of baclofen and was discharged once symptoms abated and he had a normal neurologic exam. The patient was discharged home on a phenobarbital wean.

\section{Discussion}

Baclofen is a derivative of gamma-aminobutyric acid which inhibits the transmission of both monosynaptic and polysynaptic reflexes at the spinal cord level with resultant relief of muscle spasticity [3]. The half-life of baclofen in adults is approximately 3.5 hours with $85 \%$ excreted unchanged by the kidneys. Baclofen is hydrophilic, has very low protein binding and is a small molecule $(\mathrm{MW}=213)$ [3]. Baclofen's drug properties allow the potential transplacental passage and exposure to fetuses. Intrauterine exposure to high-dose baclofen grossly affects animal fetuses. Pregnant rat and rabbit models given 7-13 times the recommended human dose of baclofen experienced more ompahloceles and incomplete stemebral ossification in rat fetuses and more un-ossified phalangeal nuclei in the fetal limbs of rabbits [6]. Fetuses of pregnant rats exposed to baclofen $30 \mathrm{or} 60 \mathrm{mg} / \mathrm{kg}$ in early gestation developed vertebral arch widening at the lower dose predisposing to a risk of spina bifida [7]. Gross abnormalities have not been reported in human fetuses exposed to baclofen [8]. Our patient was SGA; however, we cannot conclude that baclofen was the cause in this patient.

Baclofen withdrawal may be a challenge after many months of therapy and an abrupt cessation of therapy [9]. Withdrawal symptoms in adults include neurological (hallucinations, seizures), respiratory distress, cardiac arrest, and prolonged fevers [9-12]. Children and adolescents may present with absent respirations, hyperthermia, diaphoresis, seizures, dyskinesia, and rebound spasticity due to intrathecal baclofen withdrawal [13-15].

Correspondence to: Mary Temple-Cooper, MS, Pharm.D, BCPS, FCCP, Hillcrest Hospital - Cleveland Clinic, Department of Pharmacy, 6780 Mayfield Road, Mayfield Heights, Ohio 44124, USA, E-mail: mtemple@ccf.org

Key words: baclofen withdrawal, neonate

Received: April 01, 2017; Accepted: April 25, 2017; Published: April 28, 2017 
Adverse neonatal outcomes including seizures and neonatal withdrawal symptoms have been reported after maternal oral baclofen use, but not intrathecal use $[1,8]$. Reported maternal oral baclofen doses leading to seizures or other withdrawal symptoms range from 20-80 mg daily. Likely, the fact that baclofen does not leave the intrathecal space readily and the fact that intrathecal doses are very small, may have prevented neonatal withdrawal in reported cases of use during pregnancy [16].

Oral baclofen use during pregnancy does cause adverse effects in neonates. In-utero exposure to maternal oral baclofen $80 \mathrm{mg}$ divided daily resulted in seizures in a neonate who experienced baclofen withdrawal 7 days after delivery that was resistant to all anticonvulsants. ${ }^{1}$ The clinicians prescribed the same regimen we utilized $(1 \mathrm{mg} / \mathrm{kg} /$ day divided every 6 hours) and interestingly, the seizures abated 30 minutes after the first dose [1]. The withdrawal symptoms resolved within 12 hours of baclofen initiation. Our patient did not receive baclofen initially because of confounding etiologies, including multidrug exposure during pregnancy. Initially, benzodiazepine withdrawal was suspected; however, when symptoms failed to resolve, baclofen withdrawal was suspected. Our patient did not respond as quickly as the case noted; however, within 4 hours, symptoms started to resolve. A second case involved a neonate who was exposed to oral baclofen $20 \mathrm{mg}$ daily, clonazepam $1 \mathrm{mg}$ oral twice daily, and controlled-release oxycodone $50 \mathrm{mg}$ orally daily. ${ }^{14}$ This case was very similar to ours with respect to maternal polypharmacy use. This neonate experienced high NAS scores initially (6-11), but no seizures, possibly in part due to prenatal planning with a multi-disciplinary team. Baclofen administration was incorporated into the pre-natal plan for soon after delivery. They administered baclofen orally at $0.5 \mathrm{mg} / \mathrm{kg} / \mathrm{day}$ in 4 divided doses and based the dosing rationale on a combination of the previous case report, comparison of daily baclofen doses, and the pharmacokinetics of baclofen.

Our baclofen wean schedule varied slightly with those reported in the literature. The wean schedules varied possibly in part because of different dose exposures. The patient exposed to baclofen 80 daily was weaned over 2 weeks; the authors did not specify how they weaned the patient. This was a conservative wean and based on the pharmacokinetics of the drug and the lack of any adverse sequelae, was adequate. The second patient was weaned every 3 days by half the dose if the patient showed no signs of withdrawal and was discontinued after 10 days. We started to wean our patient once initial NAS scores were stable $(<8)$ for 72 hours, then every other day by $25 \%$ of the initial dose. Our patient was on baclofen 7 days and had no untoward effects after discontinuation.

Finally, the length of observation after baclofen discontinuation in the reported cases varied from ours. We discharged our patient after 48 hours of observation, while the first case just reported a two week wean and clinicians observed the neonate in the second case for 7 days after baclofen discontinuation and discharge home. We chose our observation time based off of adult pharmacokinetic data, and the fact that neonatal renal function is immature at birth. The adult half-life for baclofen is 3.75 hours. We reviewed our patient's urine output and utilized a conservative total elimination time of 40 hours to observe this patient.

Our experience adds to previous case reports of neonates exposed in-utero to baclofen and supports that all neonates exposed to baclofen in-utero require close monitoring, and a plan for possible post-natal treatment with baclofen if withdrawal symptoms are likely, arise, or persist, to prevent severe adverse outcomes such as seizures. The initial dose, tapering schedules and observation must be tailored to patient specific characteristics including maternal dose, presence of adverse effects and neonate renal function.

\section{References}

1. Ratnayaka BD, Dhaliwal H, Watkin S (2001) Drug points: Neonatal convulsions after withdrawal of baclofen. BMJ 323: 85. [Crossref]

2. Duncan SD, Devlin LA (2013) Use of baclofen for withdrawal in a preterm infant. $J$ Perinatol 33: 327-328. [Crossref]

3. Delhaas EM, Verhagen J (1992) Pregnancy in a quadriplegic patient treated with continuous intrathecal baclofen infusion to manage her severe spasticity. Case report. Paraplegia 30: 527-528. [Crossref]

4. Muñoz FC, Marco DG, Pérez AV, Camacho MM (2000) Pregnancy outcome in a woman exposed to continuous intrathecal baclofen infusion. Ann Pharmacother 34: 956. [Crossref]

5. Roberts AG, Graves CR, Konrad PE, Groomes TE, Pfister AA, et al. (2003) Intrathecal baclofen pump implantation during pregnancy. Neurology 61: 1156-1157. [Crossref]

6. Briggs GG, Freeman RK, Yaffe SJ (2001) Drugs in Pregnancy and Lactation. (6 $6^{\text {th }}$ Edn) Lippincott Williams and Wilkins Publishers.

7. Briner W (2001) The effect of GABA receptor ligands in experimental spina bifida occulta. BMC Pharmacol 1: 2. [Crossref]

8. Moran LR, Almeida PG, Worden S, Huttner KM (2004) Intrauterine baclofen exposure: a multidisciplinary approach. Pediatrics 114: e267-269. [Crossref]

9. Terrence CF, Fromm GH (1981) Complications of baclofen withdrawal. Arch Neurol 38: 588-589. [Crossref]

10. Rivas DA, Chancellor MB, Hill K, Freedman MK (1993) Neurological manifestations of baclofen withdrawal. J Urol 150: 1903-1905. [Crossref]

11. Cardoso AL, Quintaneiro C, Seabra H, Teixeira C (2014) Cardiac arrest due to baclofen withdrawal syndrome. BMJ Case Rep 2014. [Crossref]

12. Santiago-Palma J, Hord ED, Vallejo R, Trella J, Ahmed SU (2004) Respiratory distress after intrathecal baclofen withdrawal. Anesth Analg 99: 227-229. [Crossref]

13. Zuckerbraun NS, Ferson SS, Albright AL, Vogeley E (2004) Intrathecal baclofen withdrawal: emergent recognition and management. Pediatr Emerg Care 20: 759-764. [Crossref]

14. Shirley KW, Kothare S, Piatt JH Jr, Adirim TA (2006) Intrathecal baclofen overdose and withdrawal. Pediatr Emerg Care 22: 258-261. [Crossref]

15. Specchio N, Carotenuto A, Trivisano M, Cappelletti S, Vigevano F, et al. (2011) Prolonged episode of dystonia and dyskinesia resembling status epilepticus following acute intrathecal baclofen withdrawal. Epilepsy Behav 21: 321-323. [Crossref]

16. Morton CM, Rosenow J, Wong C, Kirschner KL (2009) Intrathecal baclofen administration during pregnancy: a case series and focused clinical review. $P M R$ 1025-1029. [Crossref]

Copyright: (C2017 Vijayarajah S. This is an open-access article distributed under the terms of the Creative Commons Attribution License, which permits unrestricted use, distribution, and reproduction in any medium, provided the original author and source are credited. 